\title{
Chapter 5 \\ Challenges and Opportunities for a STEM Interdisciplinary Agenda
}

\author{
Russell Tytler, Gaye Williams, Linda Hobbs and Judy Anderson
}

\begin{abstract}
There are increasing calls for the teaching of STEM within interdisciplinary settings, as a way of engaging students in authentic tasks and innovation. However there have been concerns raised about the impact of inter-disciplinary curricula on mathematics learning particularly, with a concomitant need to conceptualise how mathematics might productively interact with other disciplines in STEM settings. This chapter explores cases of interdisciplinary STEM activity that arose as part of two major Australian STEM professional learning initiatives. It focuses on the variety of curriculum structures that occurred, the challenges for schools and teachers in implementing such structures, and teacher perceptions of their experiences including student engagement. Cases of inter-disciplinary tasks/investigations are presented to explore the different ways in which mathematics is transacted, and to develop a set of principles that should govern the inclusion of mathematics in inter-disciplinary settings. The cases show evidence of increased engagement and enthusiasm of students for STEM project and investigative work, but indicate the challenge for teachers of generating productive and coherent mathematics learning in inter-disciplinary settings. The results also point to institutional and systemic barriers to the wider take-up of interdisciplinary STEM activities.
\end{abstract}

Keywords Interdisciplinary $\cdot \mathrm{STEM} \cdot$ Teacher learning $\cdot$ Curriculum $\cdot$ Project based $\cdot$ Mathematics within STEM

R. Tytler $(\bowtie) \cdot$ G. Williams $\cdot$ L. Hobbs Deakin University, Burwood, Australia

e-mail: russell.tytler@deakin.edu.au

G. Williams

e-mail: gaye.williams@deakin.edu.au

L. Hobbs

e-mail:1.hobbs@deakin.edu.au

J. Anderson

University of Sydney, Sydney, Australia

e-mail: judy.anderson@sydney.edu.au

(C) The Author(s) 2019

B. Doig et al. (eds.), Interdisciplinary Mathematics Education,

ICME-13 Monographs, https://doi.org/10.1007/978-3-030-11066-6_5 


\subsection{Introduction}

Increasingly the acronym Science, Technology, Engineering, and Mathematics (STEM) has been associated with high-level policy advocacy across the globe. Australia is no exception to this (National Council, 2015; Office of the Chief Scientist, 2012, 2014, 2016), where concern with STEM participation and performance has driven considerable governmental and media attention. A recent comparison of STEM policy and participation across 26 countries (Freeman, Marginson, \& Tytler, 2015; Marginson, Tytler, Freeman, \& Roberts, 2013) commissioned by the Australian government with an intention to 'policy-borrow' from best practice, showed high level policy concern with STEM Education and with STEM research and development. That report articulated a relative lack of coordination of curricula and teacher development in STEM education in Australia, a declining comparative performance on these tests, and declining uptake of post compulsory science and mathematics (especially higher level senior school mathematics). The report identified the difficulty with definitions of STEM, which sometimes but not always included the health sciences, agriculture and/or architecture. In schools, STEM is predominantly the province of mathematics and science, and technology subjects.

Increasingly, also, the acronym STEM has shifted from being associated with the particular collection of disciplines-S, T, E and M-to advocacy of inter-disciplinary curriculum practices built around authentic problems which involve some or all of these subjects (Tytler, Swanson, \& Appelbaum, 2015a). This shift has been evident in other countries, particularly the US, for some time (Bybee, 2013), and is associated with a number of separate strands of justification. First, the association of STEM subjects with national wealth producing agendas (Marginson et al., 2013; Office of the Chief Scientist, 2012) has led to advocacy of a focus on critical and creative thinking, problem solving, and digital literacy, as drivers of innovation in industry and the skill-set students need in a contemporary technological society (Tytler et al., 2015b). This is reflected in the increasing emphasis on inquiry, problem solving, and creativity in STEM curricula, particularly in high performing PISA (Programme for International Student Assessment) countries (Marginson et al., 2013). Second, and allied to this, there have been arguments for greater inclusion of engineering and technology in the curriculum, with a focus on design thinking and problem solving. Third, it is argued that a focus on inter-disciplinary problem solving reflects the way that STEM is practised in the world of work and research, and that a curriculum focus that students see as tackling 'real' problems is needed to engage them in STEM subjects and authentic STEM thinking, to stop the slide in participation in these subjects.

This advocacy of interdisciplinary STEM curricula at its core represents a critique of traditional science and mathematics curricula in their capacity to engage students in the critical and creative thinking and working, and the building of dispositions towards STEM subjects, that will prepare them for productive futures. A substantial body of research shows that many students develop increasingly negative attitudes to school science and mathematics across the primary and early secondary school 
years (Boaler, 1997; Goodrum, Hackling, \& Rennie, 2001; Nardi \& Steward, 2003; Tytler, Osborne, Williams, Tytler, \& Cripps Clark, 2008). Accordingly, there has been an increasing focus on student engagement with science and mathematics, and the development of dispositions towards STEM knowledge and perspectives more generally (Breiner, Johnson, Harkness, \& Koelher, 2012; Bybee, 2013; Hackling, Murcia, West, \& Anderson, 2013; Honey, Pearson, \& Schweingruber, 2014; Tytler, 2007). In Australia there has been increasing recognition of the importance of STEM thinking and skills for all students and of the need to bring school science and mathematics closer to the way science and mathematics are practised in contemporary settings (Hackling et al., 2013; Tytler, 2007; Tytler et al., 2008). In this chapter we explore the nature of interdisciplinary STEM and its potential to engage students in significant mathematics learning and in doing so engender positive dispositions.

Bybee (2013) has described a variety of arrangements by which inter-disciplinary STEM curriculum is implemented, pointing to a current state of confusion as to what might constitute a productive approach. Vasquez (2015) identifies different models of integration in which students learn through tasks that approximate STEM practices. However, serious questions have been raised about the capacity of integrated STEM models to support significant disciplinary learning in mathematics or science. Clarke (2014) points to the very different epistemic practices that constitute the individual STEM disciplines, in terms of the nature of their discursive practices, the type of reasoning through evidence, and the artefacts used and produced. He raises the question of how disciplinary constructs might be transformed in crossing disciplinary boundaries, and whether STEM knowledge and practice can be developed that are separate from their disciplinary antecedents. Lehrer $(2016,2017)$ argues that many inter-disciplinary STEM projects, while engaging for students, lack a sense of a coherent curriculum agenda and fail to engage students in the thinking characteristic of deeper disciplinary practices. They amount instead to an 'epistemic stew'. A major review of integrated STEM curricula in the US (Honey et al., 2014) found evidence of improved attitudes, but little evidence of improved learning in science or, particularly, mathematics, with mathematics teachers concerned about the level of mathematical thinking represented in these projects. A common problem with integrating mathematics into design tasks is that mathematics often plays a service role, with already-known processes used as a tool (such as calculations, or graphical work), without opportunities for the development of new mathematical insights through, for instance, students making decisions within an unfamiliar challenging problem (Barnes, 2000). Allied to these issues, there is a history of studies into integrated curriculum projects that point out the difficulty of establishing such activity within school teaching and learning cultures strongly focussed around disciplinebased subjects (Venville, Wallace, Rennie, \& Malone, 1998).

In this chapter, we draw on two significant Australian initiatives focused on schoolled innovation in STEM curricula, to explore the potentialities and challenges of pursuing mathematics learning through inter disciplinary work in STEM. The research questions we will address are: 
1. What variety of curriculum arrangements occur in these initiatives, through which inter-disciplinary STEM can be productively pursued?

2. What types of drivers, and challenges exist for these schools pursuing STEM integration?

3. What principles should apply to the productive teaching and learning of mathematics within inter-disciplinary settings?

\subsection{Two Australian STEM Initiatives}

The initiatives through which these research questions are pursued are:

1. The STEM Teacher Enrichment Academy developed and managed by the University of Sydney.

2. The 'Successful Students-STEM' program run by Deakin University within the Skilling the Bay initiative in Geelong, Australia.

The STEM Teacher Enrichment Academy, is delivered by the Faculty of Education and Social Work at the University of Sydney in collaboration with the Faculties of Science, and Engineering and Information Technology. Associate Professor Judy Anderson is the STEM Academy Director. This program is funded philanthropically with the intention of building STEM capacity through teacher enrichment and professional development. The Academy's flagship is a one-year programme (commenced in 2014) for teams of 6 secondary (students of age 12-17) teachers (preferably in subject leadership positions) from each of 12 schools each year. It is designed to enhance teachers' knowledge of content and pedagogy, inspiring them to re-invigorate their classroom practice and improve student engagement in STEM subjects. Each school includes up to two teachers within each of the STEM disciplines of mathematics, science and technology. This three phases program commences with a three-day residential workshop at the University of Sydney, followed by STEM teams returning to schools (supported by mentors), and concludes with a two-day workshop back at the university. An on-line platform is available to facilitate discussion and sharing of resources between teachers across schools during the program. The three-day residential program includes sessions facilitated by the university's academic specialists and STEM leaders, and previous academy-teacher-led, and peer-led sessions. The focus shifts over the three days from in-depth presentation of content and pedagogy in the separate disciplines, to sessions in which practical models of inter-disciplinary STEM work are presented and discussed, to each cross-disciplinary school team working together to develop inquiry-based learning approaches to teaching both within their subject discipline (Maaß \& Artigue, 2013) as well as across the subject disciplines (Campbell \& Jobling, 2014; Vasquez 2015). It culminates in school-based STEM teams planning a STEM approach to meet the needs of their students, that considers the expertise of teachers and constraints of the school context, and sharing their ideas with other STEM teams (which encourages networking across schools). In the second phase, STEM teams return to schools for at least two full school terms 
to work on developing, planning and implementing STEM strategies. They are supported by discipline-specialist professional mentors from the STEM Teacher Enrichment Academy during this time, who visit schools to provide support and assistance to teachers planning and implementing STEM strategies. The final two-day workshop focuses predominantly on school-based STEM team presentations-sharing experiences, presenting evidence of teacher and student learning, discussing issues and challenges, making closer links with other STEM teams with similar interests and/or demographics, and considering future initiatives.

The Successful Student STEM Program (STEM Program) is one of eleven initiatives of the Skilling the Bay, a government-funded initiative established in response to the changing economic climate in which major manufacturing industries in Geelong, Australia, have closed down. The region is working to stimulate a transition to a new, more knowledge-based economy. The STEM Program involves ten partner schools from the Geelong region, focusing explicitly on years 7 and 8 . Three teachers from each of ten partner schools participate in professional development over two-and-a-half years. These teachers could be mathematics, science, or digital or design technology teachers, or teachers in positions of leadership who can support a STEM curriculum change process within the school. Teachers undergo four intensive professional development sequences, with each sequence providing two intensive days focussing on building teachers' knowledge of STEM practices and pedagogies, and a third reporting and sharing day. Schools decided their own focus for STEM improvement, which could be subject-specific innovations (e.g. focusing on mathematics or science only), innovations involving integration of subjects, or innovation across a suite of subjects that promote particular STEM pedagogies (such as design-based learning). The intention is that teachers focus on their own development, but increasingly act as change agents in their school to lead sustainable STEM innovation. A Deakin University Project Officer works with schools to support their developing practice and a Secondary STEM Teacher Network has been established.

The two programs involve similar overall purposes and structures. Both programs provide support for teachers planning and working across disciplines, but there is also the possibility of single-subject innovations. For the STEM Academy workshops, although the intention was to pay equal attention to improvement in disciplinary practice, and inter-disciplinary activity, the teachers through their enthusiasm for multi-disciplinary team discussion and planning, and commenting about the value of sharing of interdisciplinary projects across schools, triggered a change in emphasis in workshop organization. Almost all the innovations involved interdisciplinary activity, with a variety of approaches. This was also true for the STEM Program. We will use this variety of approaches to STEM implementation to examine the role of mathematics in inter-disciplinary settings, first with an overview of the variety of models, and second with case studies to examine three different models of mathematics teaching and learning within an inter-disciplinary setting. 


\subsection{Scoping the Nature of STEM Innovation}

The regular reports required of schools in both projects, reporting and sharing events, field notes taken during professional development days, and de-briefing conversations with mentors, and, or, project officers, and surveys and selected interviews of teachers and students, have provided the authors (each of whom is involved with one or more of the projects) with insight into the variety of types of innovation undertaken across these schools, the drivers and challenges, and the change processes involved. Bybee (2013) pointed out that there is no single agreed curriculum model of inter-disciplinary STEM, and it could be argued that the field is currently in a confused state in terms of establishing productive approaches that fulfil the promise of advocates of interdisciplinarity. Within both Australian programs there was a wide variety of approaches and experiences, across the dimensions of: curriculum arrangements between subjects; teachers involved and nature of involvement; alignment with subject curricula (in some cases the mathematics is extraneous to curriculum requirements); the length of the initiative (from single events, to long-term projects); organizational arrangements (some schools formed a STEM committee to plan activity across year levels and subjects, such as planning a digital design focus across subjects); the nature of the evolution of the innovations (some schools had been working towards inter-disciplinary STEM curricular models prior to entering the programs); and embeddedness, and, or, sustainability of the innovation.

Across the two programs there was a variety of curriculum arrangements for pursuing inter-disciplinary STEM. These arrangements can be grouped into five broad but distinct models.

1. Cross-disciplinary activities within a single subject

There were cases of individual subjects incorporating tasks or design work around 'real world' problems that involved one or more other STEM disciplines. For instance technology design and mathematics might be incorporated into a science unit in a deliberate way, or technology projects designed to include mathematics and science thinking. In the third case below, mathematics teachers incorporated design and science work into a mathematics unit in a developing program aimed to make mathematics more authentic and relevant. In this they were able to draw on their experience as teachers of science.

2. A project based activity, often a design task, predominantly centred in one subject with related work, involving team teaching, taking place in the other subjects' curriculum time

This could involve for instance a technology class engaged in a design activity, with some of the mathematics or science needed developed separately in those classes.

3. An inter-disciplinary project based task with teachers from different subjects planning and teaching together

In this very common model a cross-disciplinary team is responsible for planning a project to which two or more of the STEM subjects contribute. Examples of such projects included the design of a grandstand involving technology and 
engineering design and mathematical work around quantity of material and calculations of water run-off and collection needed for gardens, short or long-term design challenges around model cars, an energy efficient house, or a robotics program involving coordinate geometry and working mathematically.

4. Special STEM project activities

These are special events such as robotics days supported by university engineering students, solar boat challenge days, or visits to local university STEM facilities.

5. A separate integrated STEM unit specifically designed to be interdisciplinary, with teachers from different subjects contributing

A number of schools have planned or are planning separate STEM units, often as electives, that involve the different disciplines.

\subsection{The Process of Change}

An analysis of reports from the twelve STEM Academy schools, and surveys administered to teachers from these STEM schools, yielded the following themes related to change processes.

\subsubsection{An Increasing Focus on Authentic, Inter-disciplinary Activity}

Teachers over the year became increasingly interested in, and committed to, interdisciplinary project-based learning, and confident in their assessment that this approach 'works' to engage students. Teachers worked in interdisciplinary teams to plan and became increasingly familiar with approaches in the other STEM disciplines. Some teachers (of mathematics in particular) expressed concern that these projects could compromise the integrity of mathematics. While these concerns seemed to diminish as time went on, they remained an issue for some teachers. Such concerns were in some instances exacerbated by an inability to identify where mathematics was embedded in these projects. Evidence of this came from mentor interviews and from observations of groups in workshops. In some cases, teachers of mathematics became more aware of where mathematical opportunities existed within projects over time, evidenced in presentations in the final Academy workshop. In addition, some teachers learnt to better choose projects involving mathematics that students could access and creatively explore and so deepen their mathematical understanding. Often such projects were identified through exchange of ideas between STEM teams from different schools. It is crucial that support be provided to develop such expertise in teachers, if they are to strategically represent generative mathematical thinking within inter-disciplinary projects. 


\subsubsection{Growing Confidence with Group-Based, Student-Centred Pedagogies}

Teachers expressed growing confidence with student centred problem based learning, which under-pinned most projects, and with the value of group work around authentic problems perceived to be relevant. There was a shift towards provision of hands on exploration, choice, and open-ended questioning. There were indications of an expanding pedagogical range developed through increased interactions with teachers in other disciplines, and the demands of the tasks. It seemed that enthusiasm for interdisciplinary activity was strongly associated with changed pedagogies and 'real-life' problems that led to increased student engagement with the tasks.

\subsubsection{Professional Learning Through Interactions with 'Other' Such Learners}

The major sources of professional learning reported by teachers were the ideas and experiences of other schools who had similarly grappled with inter-disciplinary innovations, learning from other subject teachers within their school, learning from their own experience in experimenting with implementing more student-centred approaches, and supporting student learning in settings in which the mathematics was linked to the 'real-world'. This points to the value of providing professional learning opportunities where teachers engage with 'similar others' in well-designed settings rather than predominantly follow the guidance of 'expert others' (Vygotsky, 1978).

\subsubsection{Collaborative Planning and Implementing of Projects}

The forming of teams and the developing of a coherent approach to STEM were crucially important aspects of innovation. In some schools the achievement of a shared purpose proved very difficult, and in all schools a process of communicating and collaborating across and beyond the team required strategic effort. Achieving buy-in from other busy teachers who did not share the same commitment, and also the wider school community, required a managed process such as providing 'tastes' of activities in a non-threatening way and/or running a project where teachers from a discipline with limited commitment in the first year were subsequently enticed through seeing the interest and learning developed by students. 


\subsection{Case Studies of Mathematics Within Inter-disciplinary Activity}

The three case studies below were chosen from more than 20 cases within the two programs, to illustrate different ways in which mathematics was included in interdisciplinary settings. The first two cases, from the STEM Academy program, were the subject of in-depth case study exploration involving site visits, observations, interviews, and collection of student artefacts. Between them they represent a variety of the dimensions listed above, and different curriculum models. The school contexts are first briefly described then the main features of the multi-disciplinary activity in each of these schools is identified.

In Case 1, a curriculum program was established where each of science, technology and mathematics collaborated on themed projects in which subject content was developed. In Case 2, a technology design-led project on go-carts was supported in the separate mathematics and science subjects, without disturbing curriculum arrangements. Case 3 involved mathematics teachers with science teaching experience pursuing STEM projects that developed mathematics capabilities in authentic settings. The role played by mathematics, and its articulation in the curriculum, differed in each case. The challenges for teaches also differed.

\subsubsection{Case 1: STEM Ed-A Collaborative Cross-Subject Program}

The first case is a small independent $\mathrm{K}-12$ co-educational school on the outskirts of a large metropolitan centre. Enrolment is approximately 450 students of which, $2 \%$ are indigenous. Forty full-time teaching staff work across the year levels with single classes in each of the primary years and usually only two classes in each of the secondary years. Due to falling enrolments in senior secondary higher-level mathematics and science, and students' poor attitudes to mathematics in particular, the Deputy Principal (who leads and teaches mathematics in the school) determined the school needed to adopt new approaches to the teaching and learning of the STEM subjects. Prior to participating in the STEM Academy, and in collaboration with the head of technology and a member of the science faculty, he trialled and evaluated a STEM project with a small group of lower secondary students in 2015 . The school also funded the development of a new learning space which students in year levels 7 and 8 (12-13 year olds) co-designed to accommodate an integrated approach to STEM teaching and learning.

With the support from the STEM Academy program, and encouraged by positive responses from students, parents and other staff members, the initial project work was expanded in 2016 to all year 7 and 8 level students. They followed the same scope and sequence of learning activities as undertaken by their predecessors the previous year. The small school size limited timetable flexibility so creative ways 
to set up an inter-disciplinary programme were explored. 'STEM-Ed' 'mathematics group' 'science group' and 'tech group' was the terminology used by the school for their program, which runs within usual classes in each discipline. Substantial redesign of the curriculum based on syllabus requirements for science, mathematics, and mandatory technology was required. The STEM team based this around 'themes' from the science syllabus document with one theme as focus in each of the four school terms throughout the year (e.g. The Rocket Project). The mathematics and mandatory technology syllabi requirements were then mapped onto these themes as far as was possible. However, time was left available in the mathematics discipline classes to teach mathematics topics which did not align with any of the identified themes. The school thus met most science and technology curriculum requirements through STEM-Ed with more of the mathematics curriculum taught external to STEM-Ed. Project briefs and assessment rubrics were designed so that students had clearly defined intended outcomes for each project, along with assessment criteria, and the expected standards. Each project brief began with a challenge then clarified the technology, mathematics and science the students were required to incorporate into their designs. Each project contributed a mark towards the final grades for the students in each STEM subject.

Students worked in small teams for 8 weeks within their separate discipline groups. It was not unusual for a teacher from one discipline to visit their class as they worked within another discipline and to take interest in what the students were achieving.

STEM-Ed mathematics group members (students) undertook particular roles within each project as well as developing ideas together. These roles included researcher, PowerPoint presentation developer and 'Think Bigger' person, who explored an idea of their own choice beyond but related to the task description. There was thus scope for autonomous and more substantial mathematical engagement in the Think Bigger aspect of the project at least. As each group presented their findings to the class, there was also opportunity for the class to learn from each group.

In the Rocket Theme Project, the mathematics component was associated with the identified theme but ran for the most part separately to the technology and science components of the project. The STEM-Ed technology group teams built and tested a rocket and in doing so, they tested possible materials as part of their STEM-Ed science group. The STEM-Ed mathematics group researched time on Mars: comparing Mars time with Earth time, considering months and seasons, and designing a school day. Two of the 'think bigger' tasks students explored were: (a) leap years on Mars, and (b) using space station data to find how long it takes for light to travel from Earth to Mars in light minutes to determine how long it would take to communicate between the two planets with text-like messages. Figure 5.1 shows some of the work undertaken by one Year 8 think bigger student who had not previously been aware of the 'Right Angles in Semi-Circles Theorem' or trigonometry.

In communicating to the teacher that he had found the distance from Earth (blue ball centre right) to Mars (at L3) (through research), and now needed to find the lengths from the satellite (at L4) to Earth and the satellite to Mars, the teacher suggested researching right angles in semi-circles, and trigonometry to see whether 


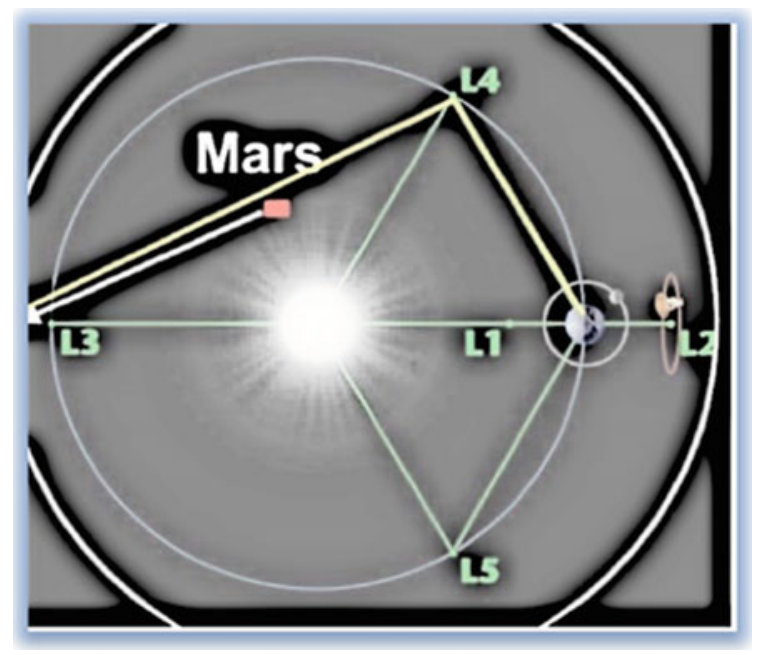

Fig. 5.1 'Think Bigger' student diagram used to work out time taken to communicate from Earth to Mars

he could find anything useful. By first encountering these mathematical ideas at a time that was useful for him, the mathematics was meaningful on first encounter. The student used this mathematics successfully to find a solution to his problem. This provides an example of a student who found a way to find some information and identified what more he needed to know to find out what he needed to know. Krutetskii (1976) identified knowing what information you still need to find as an activity undertaken by highly capable student mathematicians.

The six students interviewed (three girls and three boys) were asked questions about: how learning in STEM-Ed compared to learning in other subject areas, what they had learnt, and their career aspirations at the end of primary school and now. All students considered they had benefitted from STEM-Ed and listed this 'subject' as either their favourite or one of their favourite subjects. This included students (both girls and boys) who had been more interested in art and humanities at the end of primary school.

When you're in STEM, you learn the information, then you get to put it into a practical use in tech. Also in science we get to do field tests of what we've learned, and the same with maths. It's just very interesting.

In science in primary, it was like you need to learn this, if it's not that, you're wrong, but now it's more like you get to choose, you have more freedom and creativity. (STEM-Ed students)

As the principal was supportive and provided funds for the initial development of STEM-Ed before it was implemented in the school, and the deputy principal STEMEd mathematics team leader, was responsible for the school time-table, many of the usual problems with organisation did not arise in this school. A session for parents was 
arranged when the idea of STEM-Ed was being developed in 2013 so an interested and supportive broader school community was fostered.

Time and collaborative communication were considered essential for the development of STEM Ed. Key resources required for scaling-up were funding for collaborative time and professional learning of teachers, both of which were provided by the STEM Academy. Committing to the Academy also increased the perceived obligation of the school to progress STEM-Ed. This was extremely useful for increasing the participation of more teachers in the program. In addition, the mentor reported supporting Academy mathematics teachers as they identified key components of the mathematics syllabus associated with each of the themes and supporting their decision to leave other aspects of the mathematics curriculum to be taught independently of the STEM-Ed project work.

While it is too soon to determine whether the initiative has had an impact on postcompulsory enrolments in higher level mathematics and science, there is evidence from school data and interviews with teachers and students that attitudes to the STEM subjects have improved and enrolments in upper secondary STEM are improving for 2017. Sustainability of the initiative is imperative if this work is to continue to have an impact. The Deputy Principal was a key driver of this initiative but he is moving to another school in 2017. While there is considerable momentum in the school around the STEM-Ed approach with two of the original three teachers who developed the STEM-Ed program leaving the school, it will be critical for the head of technology to keep the momentum going. He is aware of this responsibility and is already considering which staff he will be able to draw upon to sustain the momentum, and who he will need to support as they develop their STEM-Ed skills further. He envisages a very collaborative STEM-Ed team. Plans are already in place to extend the program in 2017 into the primary school years and to introduce a Tinkerspace for the younger students. For this particular school, being small has also assisted in the expansion of the project beyond one class of students in 2015 to all students in years 7 and 8 (Age 12-13: a total of 5 classes). Executive leader support and a supportive parent community have been essential to the growth and maintenance of the initiative. Some of these characteristics contrast with the second case study school.

The STEM-Ed program at the school seemed to be a fortuitous combination of circumstances - the drive of the leadership team and energetic mathematics and technology coordinators, and the STEM Academy support, served to enlist the support of teachers and parents. Drive was needed to overcome institutional barriers such as timetabling and curriculum constraints. The question mark against a sustained STEM focus serves to underline the challenges faced in establishing a cross-disciplinary innovation of this type.

This case study shows that the structure of the 'think big' aspect of the responses to each project gives opportunities to select and explore new mathematical ideas and the nature of the task is critical to the degree to which this is possible (Kieran et al., 2008; Williams, 2002). Students require opportunities to explore unfamiliar mathematical ideas by recognizing the relevance of known mathematics, building-with it in unfamiliar sequences and combinations, and synthesising these (constructing) 
to realise something mathematically profound (Dreyfus, Hershkowitz, \& Schwarz, 2001; Williams, 2007, 2014). Key to achieving this is teacher awareness of the mathematics embedded within a STEM activity. Such activity was not occurring in all STEM-Ed projects undertaken by the maths group. For example, the Garden Project undertaken in STEM-Ed included far more revision of known mathematics (recognising shapes and their properties) than opportunities to use known mathematics to solve unfamiliar problems. One mathematics teacher emphasised the difficulty of 'tying' the mathematics into inter-disciplinary topics, and the need for support to do this:

I'm always looking out for where the maths is and then trying to tie it all back in, which is a challenge for myself. It's always hard when you're teaching indices or something where you go here's the rule, just do it, versus can we actually apply this to something that we're doing ... I'm finding it quite challenging, but I'm enjoying the challenge ... [the Vice Principal] has got a lot of maths experience and he's the one that can just whip out all these connections. So I feel supported. (STEM-Ed Mathematics teacher)

A key aspect of some mathematics teachers' experience in STEM Ed was therefore the challenge of extracting meaningful mathematics from these cross disciplinary topics in ways that can extend students' mathematical thinking. This quote implies the importance of mathematics 'experience' in developing the flexibility needed to make the connections that generate mathematical ways of thinking and working, beyond the procedural traditions of the curriculum.

\subsubsection{Case 2: Whole of Level Design Technology-Led STEM}

Unlike the first case, this case involves mathematics and science teachers supporting a Design Technology class project within mathematics classes, and occasionally becoming involved in team teaching. The mathematics was developed at different levels to match the differentiated skills of the students.

The case is a medium sized Catholic systemic co-educational secondary school located in a large provincial town with about 860 students of which $3 \%$ are indigenous and $2 \%$ have non-English speaking backgrounds. Many of the 70 teaching staff have taught at the school for some time, are very experienced and engaged in a range of ways with the local community. Similar to the first case study school, the motivation for introducing a STEM education initiative was to address the falling numbers of students doing higher level mathematics and science subjects in the senior years but of particular concern was the lower representation of female students in the STEM subjects.

Before engagement with the STEM Teacher Enrichment Academy program, there had in general been little collaborative curriculum design work in the school, including between teachers of the STEM subjects. The Academy provided the much-needed impetus to begin their journey and at a pre-Academy visit by an author of this chapter, it was evident that the team of STEM teachers had met on several occasions to plan an integrated STEM approach focused around the design work taking place in a year 
10 elective Design and Technology class. During the Academy, the teachers further developed these ideas and benefitted from feedback and suggested approaches from Academy mentors and teachers from other schools.

During 2016, the thirty students in the Design and Technology (D\&T) class taught by the leader of the STEM team in the school were to research and design a billycart. However, the intention was that all year 10 students would participate in the project work by exploring the associated relevant mathematics and science content and processes within regular timetabled lessons in those disciplines. It was fortuitous that students in the D\&T class were spread across all of the year 10 mathematics classes and science classes and were thus able to share what was happening with the billy-carts in D\&T and elicit help with the Billy-Cart Project from students in other STEM discipline classes. Thus all year 10 students took part in the design of the Billy-Carts.

The planning stage and the commitment of the STEM team in undertaking this stage throughout the Christmas holidays was crucial to the success of the BillyCart Project. An on-line website was constructed to have everything ready for the coming year. The overall program for the technology class was outlined and teachers of mathematics and science designed learning experiences for their classes based on what the students would require at particular times during the year. This meant that the technology program drove the scope and sequence of the mathematics and science classes during year 10 .

During the billy-cart construction stages, students took the billy-cart chassis or particular parts of the billy-cart (e.g. possible wheels) to their mathematics class to discuss different features and plan for the next stages of construction. Students from the technology class were able to lead learning conversations, and others would ask questions to deepen understanding as they all worked to solve problems that were encountered along the way. In mathematics, contributions to the project ranged from basic measurement and financial mathematics to applying algebraic modelling using Geogebra. To find appropriate wheels, students explored associations between features like wheel circumference and thickness, and billy-cart speed and stability, and evaluated factors they found had an impact. This overlapped with what occurred in science classes where students studied effects of forces on billy-carts and concepts associated with motion. Thus, there was some applying of previously learnt procedures in familiar contexts that led to mathematics becoming meaningful to some students who had not previously seen its relevance. At least one student, in interview, indicated this led to reconsidering mathematics subject choices. In addition, there was some recombining and/or resequencing of previously known mathematics to solve unfamiliar problems. Insights developed from this activity were about different features of wheels and how they could affect motion and the mathematics employed was crucial to finding this out.

The mathematics teachers designed and adapted tasks to facilitate learning for their streamed classes. In ascending order, these tasks focused on: making mathematics meaningful; assessing billy-carts on safety criteria; and using digital applications to identify features of billy-carts that affect its motion. 
The students who were perceived to struggle more with mathematics developed a budget for the billy-carts, made scale models using centi-cubes, sketched their models from different elevations, and designed a race-course around the school for the final event in the Billy-Cart Project. As noted by the project leader, "the students went to the Six Maps website, calculated the area and perimeter of the school, then went out and measured a course with a trundle wheel and created a 'strip map' which they then drew up". She noted the students were much more engaged than in usual mathematics lessons, spending more time on task, and if asked to do any other mathematics topics, they inquired "What's this got to do with billy-carts?" This project provided these students with opportunities to make meaning of mathematics beyond routine rules and procedures (Skemp, 1976).

The mathematically competent students investigated the mathematics behind the safety ratings applied by the Australasian New Car Assessment Program (ANCAP) then applied this mathematics to determine the safety of a late model Holden, an older car and their dream car. They sketched what they saw, marked in what they were able to measure, and worked out what mathematical information they still needed to find because it was unable to be measured, again showing a capacity to identify required information (Krutetskii, 1976). This task created discussion as students struggled to work out what they needed to know how they might be able to find out. When students found that the hypotenuse could not be shorter than the height of the triangle, informal development of ideas about the relative lengths of sides of triangles was stimulated for some students. These students had thus discovered and decided to explore a mathematical complexity (Williams, 2007).

The students that teachers perceived to be highly capable mathematically used a Geogebra animation designed by their teacher (physics teacher member of the STEM team) to explore the impact of various factors on the speed of billy-carts based on physics formulae.

While much of the project work occurred in lessons taught by the relevant subject teacher, some team teaching occurred during the year. A positive outcome from this approach was that the technology students appreciated their mathematics teacher coming to their technology class to help them with their billy-cart designs- the usefulness of mathematics became more evident and they were able to 'transfer' knowledge more readily between their STEM subjects.

Several key features of the approach at this school lead to the success of the STEM program. These included the passion, vision, and leadership of the technology coordinator who was the key driver in designing the Billy-Cart Project, developing a collaborative STEM team, and co-ordinating meetings with other staff members involved, and engaging the community with the project. The STEM Academy schoolbased team worked through the Christmas holidays to prepare everything for staff and students when they returned to school. The large number of teachers enticed into the project by the STEM team provided opportunities to source many types of expertise. Community engagement was critical to the success of this project with, for example, teacher contacts with the Vintage Car Community resulting in a Motor Show where cars from the early 20th Century through to the present day were displayed on the 
oval. There was also ongoing encouragement and support from the Regional Catholic Education Office who subsequently drew on the expertise this team developed.

The overall engagement of a large number of teachers from the school, not just the six teachers in the STEM Academy was crucial to the degree of success achieved and should impact on the sustainability of the program into the future. In the final report to the STEM Academy, the team leader wrote:

A key success to the STEM project at [this school] was the involvement of the TAS (Technology), Mathematics and Assistant Science co-ordinators. This enabled effective communication within and across KLAs [Key Learning Areas]. There were 6 Science teachers involved in this project, together with 8 Mathematics teachers and 1 Design and Technology teacher. In addition, 2 staff played a significant role in the support of IT and implementation of STEM at a leadership level in the school. A total of 17 staff were involved in this pilot project, this equates to $25 \%$ of the full-time teaching staff at [the school].

This school has played a leading role in stimulating interest in STEM Education in other schools in the region and beyond and providing professional learning for them. This should also impact on project sustainability.

Student interviews confirmed the success of the STEM approach which heightened their enthusiasm for the STEM subjects. The Design and Technology (D\&T) students who had previously not looked forward to mathematics and science described how STEM activity had given them focus, and learning that had resulted:

Yes, sort of like we were saying before, like when you look at the timetable for the day and it's only got three lessons on the same thing. So you walk into the day thinking like, you know, three lessons on the billy cart and how it works and stuff like that, ... so you sort of get three lessons to work on one thing, rather than one hour ... You've got to change it up sort of thing. So it's definitely helped me,

It also led to an appreciation of collaborative group work:

... if you come to a problem, you've got to try and create another alternate way of fixing that and like when you're by yourself it's a bit hard. Like you try and think like, "I don't know how I can do this," but when there's two other people in the group that can combine ideas, like have a real good idea that fixes it.

People know different stuff and they bring different things to the table and have more options.

Participating in STEM projects has led to some of these D\&T students who had not considered doing mathematics in year 11 reconsidering their options. For example, when asked whether he had considered mid-level mathematics prior to the project, one boy stated: "No not at all!" The project had influenced this student's subject choices: "I think it's definitely helped a little actually because of Maths ... [I've] been more engaged ... just with the stuff we're doing, so from that-wheels and angles and stuff like that".

The energy and enthusiasm of this school for designing new and more integrated STEM approaches is still evident with plans to design a project called "Save the Earth" for year 7 students towards the end of 2016. To facilitate this, and further STEM work, the Deputy Principal who manages the timetable has been co-opted as a member of the STEM team so that school structures which were problematic or fortuitous during 2016 can be planned in 2017. These included timetabling all 
members of the STEM team as teachers of year 10 classes, providing timetabled sessions where STEM team members can continue to carry out professional learning for other teachers during their classes in 2016, and timetabling meeting times for the STEM team. In addition, there are provisions for the introduction of a new elective subject for year 9 and 10 students, implemented in 2017.

Opportunities for students to engage with mathematics in unfamiliar ways were increased by the STEM team's ability to think creatively in developing and extending the program and bringing other teachers on board. The passion and energy of the school-based academy STEM team spread through the broader STEM participating teachers at the school.

\subsubsection{Case 3: Engaging in Mathematics Through Within-Subject STEM Investigations}

Case 3 involved years 7-8 mathematics teachers developing STEM investigative projects within the mathematics curriculum in order to better engage students conceptually. Case 3 is a state girls' secondary college, which joined the STEM Program in order to attend to a continuing problem of students entering the school at year 7 with weak mathematics background, low aspirations towards STEM careers, and a decline in senior mathematics and science enrolments. In order to address these issues, a teaching team focussing principally on mathematics was chosen to participate in the STEM Program. The teachers' framing of STEM was largely based on a need to improve students' engagement and application of mathematical ideas, so was largely focussed on improving mathematics teaching and learning. The school endeavours to have the same teacher teaching mathematics and science at years 7 and 8 , allowing for some co-ordination of the teaching of science and mathematics. Therefore, two of the activities generated by the team have scientific concepts embedded in them to frame the nature of the problem being explored mathematically.

During the first professional development session, problem solving, modelling in mathematics, and collaboration during problem solving, were introduced to the participating teachers. The teachers from School 3 were intrigued by this problemsolving approach, particularly because they had been experimenting at the school already in a year 9 mathematics elective where students are required to build a chair and explore the mathematics involved. This activity was taught by a single teacher in an elective class, but the STEM program teachers decided to expand this approach into the mainstream mathematics classes at years 7 to 9 . In the first year of the STEM Program (professional learning sequence 1) the teachers developed a ramp investigation for year 7 classes. In year 2 they refined the ramp investigation, and developed two new investigations for year 8 students: a tank investigation (professional learning sequence 2 ) and a clothes investigation (professional learning sequence 3 ). The process of developing the investigations evolved over time, and refinement and redevelopment is a crucial part of ensuring the investigations are manageable for students, 
and that the necessary scaffolds are provided through differentiation of the tasks and provision of resources. The intention is to have one investigation per semester through years 7 to 9 . The investigations last for about two weeks; any longer than this and the teachers found that the students lose momentum.

The three investigations are described in Table 5.1 structured under the headings 'Immersion', 'Mini-inquiries', and 'The big question', which drove the structure in each investigation.

The process of investigation is illustrated by the Clothes investigation in which the following steps were carried out.

The first step was posing the question. Students were encouraged to consider at what time during their school life they need the most amount of new clothes. Thinking of their parents who need to balance their finances, students are asked, wouldn't it be good to know the budget for when they need to buy the most clothes? A PowerPoint presentation was given to the class, and support materials were available on the school intranet.

Students then undertook mini-inquiries where they collected the heights of students in their school, a local primary school, as well as secondary data from the Bureau of Statistics (being a girls' school they needed data for boys). One teacher stated that when discussing the data collected from within the school, one student queried the result that the average of year 9 was taller than year 10:

\footnotetext{
I said have another look at the data, and she said that one student had recorded themselves as $185 \mathrm{~cm}$ tall. And then she looked at how tall that is. And I said do you know a year 9 student who is that tall? Well, no. And then we opened up the discussion about outliers, which is probably a little bit beyond where she's at. But I did speak to some of the Further Maths teachers in year 12, and they said that it's often a conversation that kids don't have and they don't know what you mean by an outlier. But even if I've sown that seed, then when it comes up later they might be able to recall what we talked about. So, she decided to discard that bit of information.
}

Having examined data from primary and secondary schools, students were asked if they had enough data to answer the question. Students needed to be led to consider the predominance of female data, and some students were not willing to examine this limitation of the data. Some students did realise the need for more male data, and discussed the need for secondary data. They searched the Australian Bureau of Statistics website and found some male data and the teacher made that available for the students: "Some of them were finding it hard to get the data themselves, so I randomly selected different year levels' male data and if they wanted they could access that".

In addition, students were asked to consider data from home, for example growth marks on the door-frame showing height at different ages.

In preparing for the report, the students were asked to prepare a plan for responding to the question. The report was aimed at parents to support their budgeting for new clothes. The instructions included attention to hypothesising, arguing and concluding, communicating, and using appropriate mathematical representations. The task needed to be differentiated by limiting or opening up the scope of the problem 


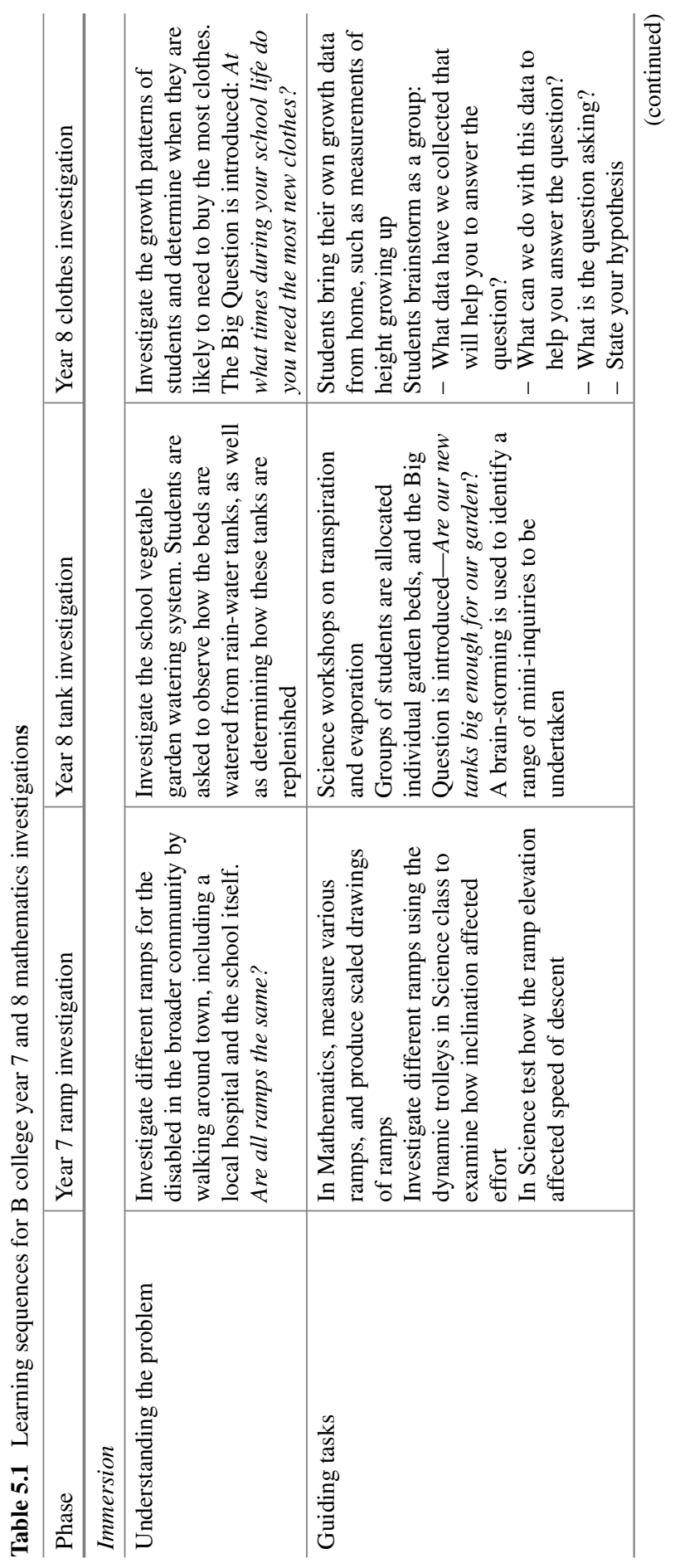




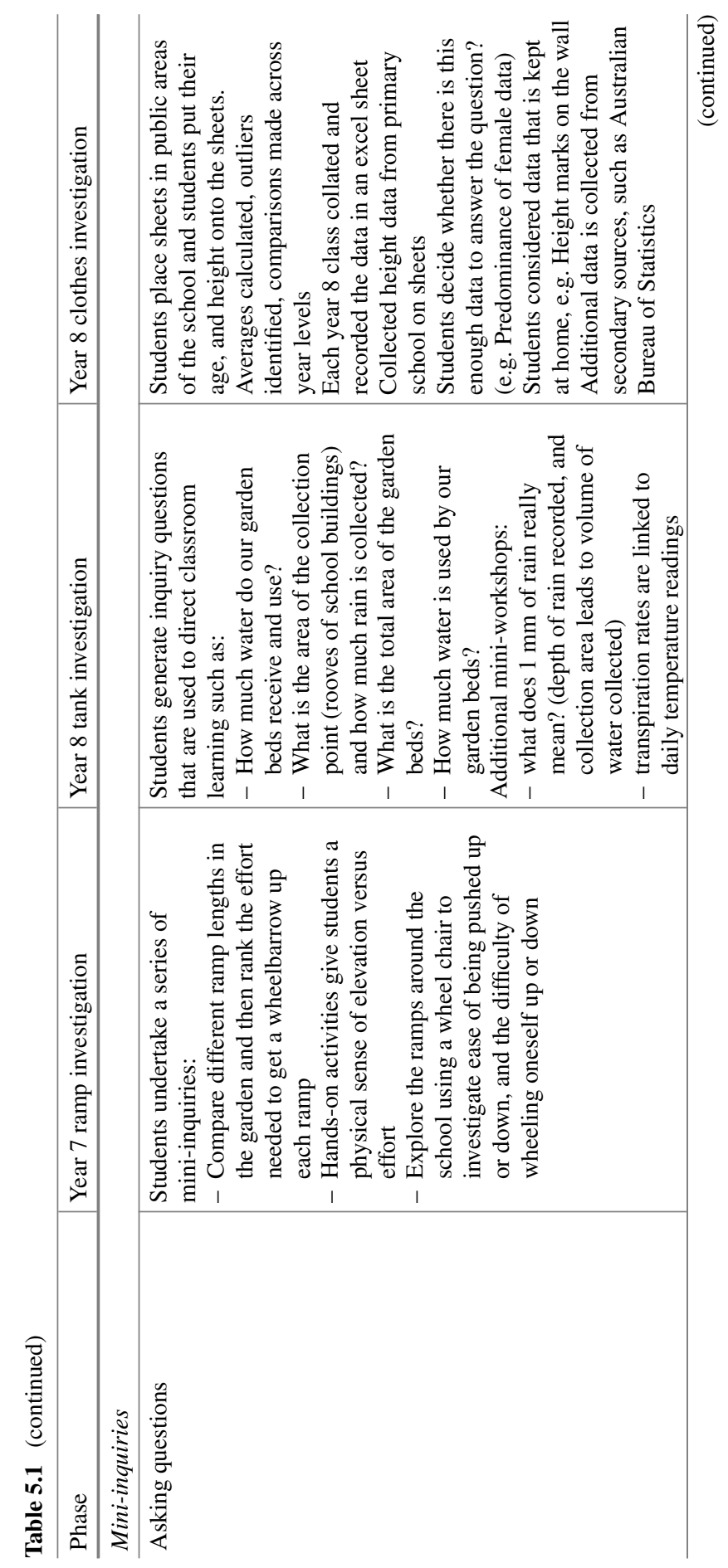




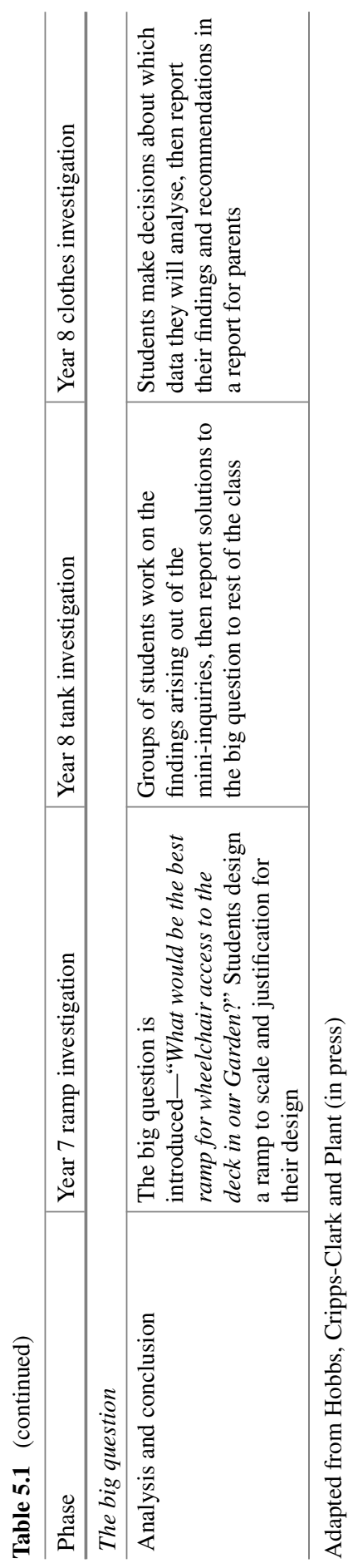


that students reported on. For example, students decided whether they made recommendations for females, males or both. A teacher explained the importance of scaffolding the students:

We do try and scaffold it. So, for some students, if the question is too big then maybe focus just on females, maybe reduce the amount of data as it was a bit overwhelming for some students - different ways to differentiate the task. I just speak to students individually to see how they're going and suggest where they can reduce it and give them some support in that way.

\section{Developing a Culture of Investigation}

Through these open investigations, the teachers are attempting to bring in real world mathematics where students can see the application of mathematical concepts. One teacher reported that as the investigations become more entrenched into the normal practices of the teachers, they have allowed the staff and students to see learning mathematics in a new light, not so routine or abstract. The teachers have found that students are more engaged, as the investigations relate to questions that are relevant to students' lives. In making this new approach sustainable, there is a need to bring other teachers on board and embed the practice in the school so that there is an expectation and willingness to use this approach.

The teachers reported that more mathematics staff are implementing these investigations in their classroom. Initially just the three STEM Program teachers developed and implemented them for their year 7 classes, but over time some new year 7 staff have started implementing the ramp and water investigations: "Hopefully, we are getting staff experimenting with this teaching practice and be a bit confident to go into the classroom and use these teaching methods".

Recognising the need to change is a pre-condition for changing practice; the STEM Program teachers saw the incorporation of STEM practices as a valuable conduit for promoting a new way of learning that promotes problem solving and creativity. In thinking about some of the key outcomes of being involved in the program, one teacher mentioned that "Our big push is that engineers are solving questions" and that this vision underpins their planning for these investigations. One teacher stated that these investigations are a way to bring STEM practices into their teaching, not just when completing these activities, but staff are tending to apply these teaching practices in their general teaching: "They become your 'default' position, that you don't always just have that really structured or skill-based teaching of mathematics". One teacher commented further: "It's not just about the investigations, but trying to model to other teachers that STEM practices should be part of your teaching. Makes teaching more exciting, also makes the maths more exciting".

Documenting both the activities and the process of implementation was shown to be critical to encouraging uptake of the activities by other teachers and ensuring the spirit of the pedagogy is maintained. As the activities are applied by the other mathematics teachers, further materials are being developed to guide the teachers on how to support the students in a differentiated way. For example, a graduate 
teacher developed a booklet to help himself understand how to run the units and then another teacher developed the booklet further. Initially the booklet was intended for the teachers but then they decided it would also be useful for students, particularly students needing additional support such as guidance in collecting and representing data. One teacher said that this type of material "embeds it a bit more" in the school, so their intention is to document the other units in a similar way to ensure the activities are not shelved.

Important factors in this sustainability are teachers recognising a need for change, and that the proposed change is effective. The teachers regularly gathered feedback from the students as they were developing the units. They have found that, for the Tank activity, for example, students appreciated the opportunity to see how mathematics related to their real life and the differentiated nature of the tasks (such as through multiple entry and exit points), but that some students still found the task difficult. Using a Plus/Minus/Interesting (PMI) framework, students reported comments such as the following:

- PLUS: "I liked how it was a real-life problem. It made me more interested in doing my maths work"; "I liked how we worked independently"; "Making the graph was fun"; "I liked working through the questions in my own time"; "I like that it was real work maths and it actually meant something to use because it is where we live".

- MINUS: "I didn't really enjoy that I didn't get to start the question because people didn't hand in their data"; "Some of the questions were very difficult"; "Some of the calculations I found hard to do".

- INTERESTING: "I found it interesting how much water Geelong used".

Such feedback was shown to be important in refining the activities and their implementation, but also in promoting these STEM teaching practices within the school more broadly. The data is being reported to other teaching staff and school leadership in order to inform the broader STEM agenda currently being developed at the school.

\section{Developing the Tasks}

Once the open investigations structure was developed and trialled by the teachers, the difficulty they then faced was in deciding which topics could be approached through an open question and how to make the problem 'relevant' for the students. The teachers also decided to focus on areas of the curriculum that were not typically addressed adequately. Two teachers explained with respect to the Ramp activity:

This task came from one teacher saying we want to do linear relationships, so we sat down and thought how can we turn that into a question? And at the start we were struggling. But it is interesting that when you get your mind into that way of thinking it's interesting where you'll end up.

This is how we've come up with the questions. We look at what we teach across the whole year. For example, for the ramp investigation, we decided we didn't do enough geometry, 
didn't cover triangles that well, so look at things that we normally skim over and try to make that more in-depth.

The tasks were generally developed to be contained within the mathematics classes, but teachers who were also the science teachers could make links to concepts from other subjects, particularly science concepts in the Ramp investigation and transpiration in the Tank investigation. The real-life problems that they selected are by their nature complex in terms of knowledge needed to solve the problem, as well as in the possible solutions and mathematical thinking involved.

\subsection{Discussion}

These case studies have presented three different approaches to interdisciplinarity in their curriculum arrangements and the way the mathematics intersected with other subjects. In Case 3 the project sat entirely within the mathematics subject but was inter-disciplinary in the way the mathematical ideas intersected with the other disciplines in approaching the task. In each of the investigations the mathematics was central to resolving the task. Within cases 1 and 2 there was variation depending on the particular project, or on the particular mathematics class. Sometimes, as with the billy-cart wheel investigations, the mathematics was embedded, and differentiated. In other cases, the mathematics was extended into aspects extraneous to the central theme, to develop mathematical thinking unhindered by that requirement, such as with the exploration of geometric shapes associated with the garden design or the calculation of astronomical distances (Fig. 5.1). This further mathematical thinking was often exploratory. In all three cases, mathematics and other knowledges were developed side-by-side in a way that intersected with but was not totally confined by the problem, and fed off the authenticity of the problem to engender interest and further develop the mathematics. In each case also the STEM approach was introduced with the intention of enlivening the mathematics curriculum to develop more positive dispositions in students towards mathematics and STEM. There is evidence in these case studies that this manner of teaching mathematics is successful in doing this.

In each of these schools, a large portion of the mathematics curriculum was left undisturbed by the STEM sequences, more so in some cases than others. Schools have not yet focused to a large extent on building a coherent curriculum through STEM although each has made a start: Case 1 school has mapped science and technology against interdisciplinary learning at year 7 and 8 and will continue to develop this more, Case 2 school has focused attention on drawing out the curriculum links in projects they have considered to have potential, and Case 3 school has focused on identifying a project that fits with several areas of mathematics within the curriculum. It is clear that in engagement with ideas and responsiveness to mathematical ideas associated with authentic problems, that the grounding of mathematical processes within such tasks can occur in areas as diverse as motion, functions, statistics, mea- 
surement, trigonometry, descriptive geometry and geometrical theorems, and number patterns. Where there is significant mathematics involved, there are opportunities for analysis, modelling, design, evaluation, and synthesis that include requirements to transfer between representations. Situating these tasks in community settings, and providing teachers with ongoing access to the ideas of 'similar others' can be crucial as can access to strategic leaders who are willing to listen and provide the necessary support to help to overcome the challenges that STEM teams encounter. There was also evidence of teachers supporting the types of high-level mathematical thinking just described, arising from some of these tasks. There was evidence also of mentors providing valuable support for teachers to identify, interpret, and create mathematical opportunities pertinent to particular STEM tasks, implying that this way of working is challenging for teachers of mathematics who are used to working in more systematically framed mathematics curricula. This points to the importance of raising teacher expertise in identifying and embedding substantial mathematical opportunities within tasks. There was ample evidence in these and other cases of teachers' enthusiasm for grappling with these tasks, their perception of students' enthusiasm, and student reported valuing of this way of learning.

From these case studies and experience with the programs more generally, and drawing on findings from the research literature, we argue that there are a number of principles that underpin productive mathematics learning within interdisciplinary activity:

- Tasks should have an affective payoff-students need to want to do it;

- Tasks are open and emphasise problem solving that involves creative use of mathematics rather than external control of student thinking;

- Tasks encourage/entice students into using mathematics in unfamiliar ways, involving new representational moves, transformations, sequencing and combining of mathematical ideas, and synthesising ideas so there are opportunities for something mathematically profound to emerge; and that

- Where tasks do not fit with the above principles, but primarily involve using previously known mathematics as a tool for exploring authentic problems, the relevance of mathematics can be increased if it is seen to lead to fresh insights into the problem.

\subsection{Conclusion}

In this chapter, we have described the progress of teachers and schools in developing approaches to inter-disciplinary STEM curriculum innovation within two substantial Australian professional learning programs. We have identified the different ways in which such inter-disciplinary work can proceed, both in terms of productive approaches to the relations between teachers and STEM subjects, the ways in which mathematics teaching and learning can operate productively in an inter-disciplinary setting, and ways some of the challenges encountered have been overcome. Evidence 
from these programs suggests that while there are reported concerns (Honey et al., 2014) about the integrity of the mathematics curriculum and mathematics learning in such projects, this was not a significant feature of what occurred in these schools. There was some indication that teachers' capacity to develop mathematical components of projects that conformed to the principles above improved over time, aided by sharing ideas across schools (with similar others) and sometimes input from mentors (expert others). At least some of the teachers had previously experimented with inter-disciplinary STEM projects for several years in their schools. This suggests a need for such projects to extend over time to provide opportunities for teachers to be supported as they experiment to develop appropriate pedagogies and become able to identify and/or embed substantial mathematics within interdisciplinary tasks.

Enthusiasm for inter-disciplinary work increased for teachers in these schools as their students found these activities absorbing and engaging. This was true both where the activities involved teachers from a number of STEM disciplines, and also where an inter-disciplinary approach was embedded within the mathematics program. One of the key arguments therefore is that at least some of the mathematics curriculum can be learnt in an inter-disciplinary fashion to harness student enthusiasm through its depiction of mathematics as relevant in interesting and unexpected ways. In each of these cases mathematics provides a window through which patterns and structures in natural or designed systems can be quantitatively discerned and further explored.

There is a significant question, however, about the way mathematics is enlisted and used in STEM activities, and the extent to which such inter-disciplinary work can address the mathematics curriculum. This is related to our argument that interdisciplinary project work, if it is to support significant mathematical learning, must preserve the epistemic integrity of the subject. That is, it should allow the free play and development of mathematical thinking and working, rather than simply apply pre-existing knowledge. Following this, if we are to give interdisciplinary STEM activities greater representation in the mathematics curriculum, we need to investigate how to do this in a coherent way that builds foundational knowledge.

Even where such conditions are not met, the student enthusiasm for STEM tasks, including mathematics tasks, reported by some teachers and students, provides a justification for inclusion of inter-disciplinary STEM activities within the mathematics curriculum. The development of positive dispositions in relation to mathematics, particularly mathematical problem solving (see for example Williams, 2014), is increasingly recognized to be an important curriculum purpose. Further, the argument that these inter-disciplinary activities promote critical and creative thinking beyond what is allowed in traditional approaches, is exemplified to varying extents in these case studies, through the innovative applications of mathematical ideas to situations such as creating strip maps for a race course, investigating the mathematics behind safety ratings, linking billy-cart motion to design features, and developing mathematics to design ramps.

Finally, what comes across in these cases, and through wider experience of these two programs, is the challenge presented in developing a sustainable interdisciplinary STEM program. It seemed there were a number of conditions that needed to be in place to establish such programs, including resources and ongoing profes- 
sional learning support, champions within the school, and support from leadership within the STEM subjects and in the school generally. The programs were in need of ongoing maintenance, due to the demands of traditional views of curriculum and assessment, timetable constraints, and presumptions about curriculum structures. However, teacher enthusiasm for change was powerful in each case. Historically, integrated curriculum advocacy has never prevailed against disciplinary interests. The question we might ask of current calls for interdisciplinary STEM is: Will it be different this time? Perhaps, with calls for a re-purposing of education, significant changes in the way knowledge is accessed and used, alongside teacher appreciation of student engagement in these activities, inter-disciplinary STEM will become an established phenomenon. Perhaps more importantly, it will provide impetus for reforming school mathematics practices in positive ways.

\subsection{Coda}

In this chapter we have presented three cases of schools situating mathematics teaching and learning in interdisciplinary STEM settings. The cases illustrate different curriculum arrangements through which students engaged mathematically with authentic design or investigative tasks, different school histories underpinning these, and different challenges faced by mathematics teachers. There are a number of implications we draw out from this comparative study.

\subsubsection{The Commonalities in Mathematics Through STEM Despite the Variety of Approaches}

The curriculum arrangements differed across the cases in the way the mathematics teachers interacted with technology and science teachers. The key feature however, that we should take as the fundamental principle of STEM-focused mathematics, was in each case the application of mathematics to projects that were 'authentic' and meaningful to students and involved them either in developing mathematics that was new, or applying known mathematics in new ways.

\subsubsection{The Role of Disciplines}

In no case was it argued that mathematics should evolve into an interdisciplinary practice that was distinct from disciplinary practices. Rather, what was involved was the re-alignment of mathematical thinking and working to more problem oriented 
and relevant contexts. One might argue that this constitutes a more natural role for disciplinary thinking.

\subsubsection{Principles Underpinning Mathematics in Interdisciplinary Settings}

From the cases and the literature we argue that for productive mathematics learning in interdisciplinary settings, tasks should (a) engage students' interest, (b) involve problem solving, (c) involve students in using mathematics in unfamiliar and creative ways, and (d) lead to fresh insights into the problem being pursued.

\subsubsection{The Challenge for Teachers}

Teachers of mathematics have found it challenging to develop productive learning opportunities from STEM problem solving and investigative tasks. This involves a different perspective and perhaps skill set that takes mathematics away from traditional ordered sequencing to a more responsive view of mathematics learning and knowing. However, there was evidence that teachers became more adept at this over time. In Case 2, teachers were able to adapt the tasks to different levels of students' mathematical capabilities. The second challenge, one that teachers seemed to readily adapt to, was the more student centred and open pedagogies often involved in these projects. In Case 3 this adaptation was an explicit focus for the teachers involved.

\subsubsection{Conceptual Engagement of Students}

There was evidence, in all cases, of students being more enthusiastic about mathematics through these interdisciplinary tasks, and it seemed more conceptually engaged with mathematics. In Case 1 this was aligned with a feeling that the curriculum needed to encourage deeper and more sustained learning, and the ways that contemporary students like to learn. From students' viewpoint, the development of mathematics that was immediately applicable and helpful in problems they felt invested in, provided significant motivation. 


\subsubsection{The Conditions for Sustainable Innovation}

In all cases the development and sustaining of these curriculum innovations depended on high level support from principals, and discipline leaders. In some cases, it involved science, technology and mathematics coordinators who had a similar vision, or in other cases teachers who taught across more than one of these areas.

\section{References}

Barnes, M. (2000). 'Magical' moments in mathematics: Insights into the process of coming to know. For the Learning of Mathematics, 20(1), 33-43.

Boaler, J. (1997). Experiencing school mathematics—teaching styles, sex and setting. Buckingham: Open University Press.

Breiner, J. M., Johnson, C. C., Harkness, S. S., \& Koelher, C. M. (2012). What is STEM? A discussion about conceptions of STEM in education and partnerships. School Science and Mathematics, 112(1), 3-11.

Bybee, R. W. (2013). The case for STEM education: Challenges and opportunities. Arlington, VA: National Science Teachers Association.

Campbell, C., \& Jobling, W. (2014). STEM education: Authentic projects which embrace an integrated approach. Australian Journal of Technology Education, 1, 29-38.

Clarke, D. (2014). Disciplinary inclusivity in educational research design: Permeability and affordances in STEM education. In Invited Keynote at the International STEM Conference, Vancouver, July 2014. http://www.djclarke.iccr.edu.au/.

Dreyfus, T., Hershkowitz, R., \& Schwarz, B. (2001). Abstraction in context II: The case of peer interaction. Cognitive Science Quarterly, 1(3), 307-368.

Freeman, B., Marginson, S., \& Tytler, R. (2015). The age of STEM: Educational policy and practice across the world in science, technology, engineering and mathematics. London: Routledge.

Goodrum, D., Hackling, M., \& Rennie, L. J. (2001). The status and quality of teaching and learning of science in Australian schools. Canberra: Australian Department of Education Science and Training.

Hackling, M., Murcia, K., West, J., \& Anderson, K. (2013). Optimising STEM education in WA schools, Part 1: Summary report. Edith Cowan Institute for Education. Retrieved from http:// www.acola.org.au/PDF/SAF02Consultants/SAF02_STEM_\%20FINAL.Pdf.

Honey, M., Pearson, G., \& Schweingruber, H. (2014). STEM integration in K-12 education: Status, prospects, and an agenda for research. Washington, DC: National Academies Press.

Kieran, C., Guzman, J., Bolleau, A., Tanguay, D., \& Drivjers, P. (2008). Orchestrating whole class discussions in algebra with the aid of CAS technology. In O. Figueras, J. Cortina, S. Alatorre, T. Rojano \& A. Sepulveda (Eds.), Proceedings of the 2008 Joint Meeting of the International Group for the Psychology of Mathematics Education and the Group for the Psychology of Mathematics Education Meeting of North America (vol. 3, pp. 249-256). Mexico: Cinvestat-UMSNH.

Krutetskii, V. (1976). Psychology of mathematical abilities in schoolchildren. In J. Kilpatrick, \& I. Wirzup (Eds.), (J. Teller, Trans.). Chicago: University of Chicago Press (Original work published in 1968).

Lehrer, R. (2016, October). Perspectives on elementary STEM education. Keynote address at the forum: Putting STEM education under the microscope. Melbourne: Deakin University. https://blogs.deakin.edu.au/steme/wp-content/uploads/sites/39/2017/04/Lehrer-Deakin STEM_2_reduced.pdf. 
Lehrer, R. (2017, September). Considering epistemological junctions when designing for interdisciplinary learning. Paper presented at the Conference of the European Association for Research in Learning and Instruction (EARLI), Tampere, Finland.

Maaß, K., \& Artigue, M. (2013). Implementation of inquiry-based learning in day-to-day teaching: A synthesis. ZDM Mathematics Education, 45(6), 779-795.

Marginson, S., Tytler, R., Freeman, B., \& Roberts, K. (2013). STEM: Country comparisons. Melbourne: The Australian Council of Learned Academies. Retrieved http://www.acola.org.au.

Nardi, E., \& Steward, S. (2003). Is mathematics T.I.R.E.D? A profile of quiet dis-affection in secondary mathematics classrooms. British Educational Research Journal, 29, 345-366.

National Council. (2015). National STEM school education strategy, 2016-2026. Retrieved http:// www.educationcouncil.edu.au/site/DefaultSite/filesystem/documents/National\%20STEM\% 20School\%20Education\%20Strategy.pdf.

Office of the Chief Scientist. (2012). Health of Australian science. Canberra: Commonwealth of Australia.

Office of the Chief Scientist. (2014). Science, technology, engineering and mathematics: Australia's future. Canberra: Commonwealth of Australia. Retrieved http://www.chiefscientist.gov. au/wpcontent/uploads/STEM_AustraliasFuture_Sept2014_Web.pdf.

Office of the Chief Scientist. (2016). Australia's STEM workforce: Science, technology, engineering and mathematics. Canberra: Commonwealth of Australia.

Skemp, R. (1976). Relational understanding and instrumental understanding. Mathematics Teaching, 77, 20-26.

Tytler, R. (2007). Reimagining science education: Engaging students in science for Australia's future. Australian Educational Review, 51. Melbourne: ACER. Retrieved http://research.acer. edu.au/aer/3/.

Tytler, R., Osborne, J., Williams, G., Tytler, K., \& Cripps Clark, J. (2008). Opening up pathways: Engagement in STEM across the Primary-Secondary school transition. Canberra: Australian Department of Education, Employment and Workplace Relations. Retrieved http://pandora.nla. gov.au/tep/88047.

Tytler, R., Swanson, D. M., \& Appelbaum, P. (2015a). Subject matters of science, technology, engineering, and mathematics. In M. F. He, B. D. Schultz, \& W. H. Schubert (Eds.), The Sage guide to curriculum in education (pp. 27-35). Thousand Oaks, CA: Sage.

Tytler, R., Symington, D., Williams, G., White, P., Campbell, C., Chittleborough, G. ... Dziadkiewicz, N. (2015b). Building productive partnerships for STEM education: Evaluating the model and outcomes of the scientists and mathematicians in schools program. Melbourne: Deakin University. Available at: http://www.scientistsinschools.edu.au/downloads/ SMiSEvaluationReport2015.pdf.

Vasquez, J. (2015). Beyond the acronym. Educational Leadership, 72(4), 10-15.

Venville, G., Wallace, J., Rennie, L. J., \& Malone, J. (1998). The integration of science, mathematics, and technology in a discipline-based culture. School Science and Mathematics, 98(6), 294-302.

Vygotsky, L. S. (1978). Mind and society: The development of higher psychological processes. In M. Cole, V. John-Steiner, S. Scribner, \& E. Souberman (Eds.) (J. Teller, Trans.). Cambridge, MA: Harvard University Press.

Williams, G. (2007). Abstracting in the context of spontaneous learning. Mathematics Education Research Journal (Abstraction, Special Edition), 19(2), 69-88.

Williams, G. (2002). Associations between mathematically insightful collaborative behaviour and positive affect. In A. Cockburn \& E. Nardi (Eds.), Proceedings of the 26th Annual Conference of the International Group for the Psychology of Mathematics Education (Vol. 4, pp. 401-408). Norwich: University of East Anglia.

Williams, G. (2014). Optimistic problem-solving activity: Enacting confidence, persistence, and perseverance. ZDM-The International Journal on Mathematics Education, 46(3), 407-422. https://doi.org/10.1007/s11858-014-0586-y. 
Open Access This chapter is licensed under the terms of the Creative Commons Attribution 4.0 International License (http://creativecommons.org/licenses/by/4.0/), which permits use, sharing, adaptation, distribution and reproduction in any medium or format, as long as you give appropriate credit to the original author(s) and the source, provide a link to the Creative Commons licence and indicate if changes were made.

The images or other third party material in this chapter are included in the chapter's Creative Commons licence, unless indicated otherwise in a credit line to the material. If material is not included in the chapter's Creative Commons licence and your intended use is not permitted by statutory regulation or exceeds the permitted use, you will need to obtain permission directly from the copyright holder. 